California State University, Fullerton Department of Civil \& Environmental Engineering

Presented by : Nidhi M Modha

Faculty Advisor: Dr. Pratanu Ghosh (pghosh@fullerton.edu)

\title{
Investigation of Modulus of Elasticity and Surface Electrical Resistivity in High Performance Concrete(HPC) Using Natural Zeolite
}

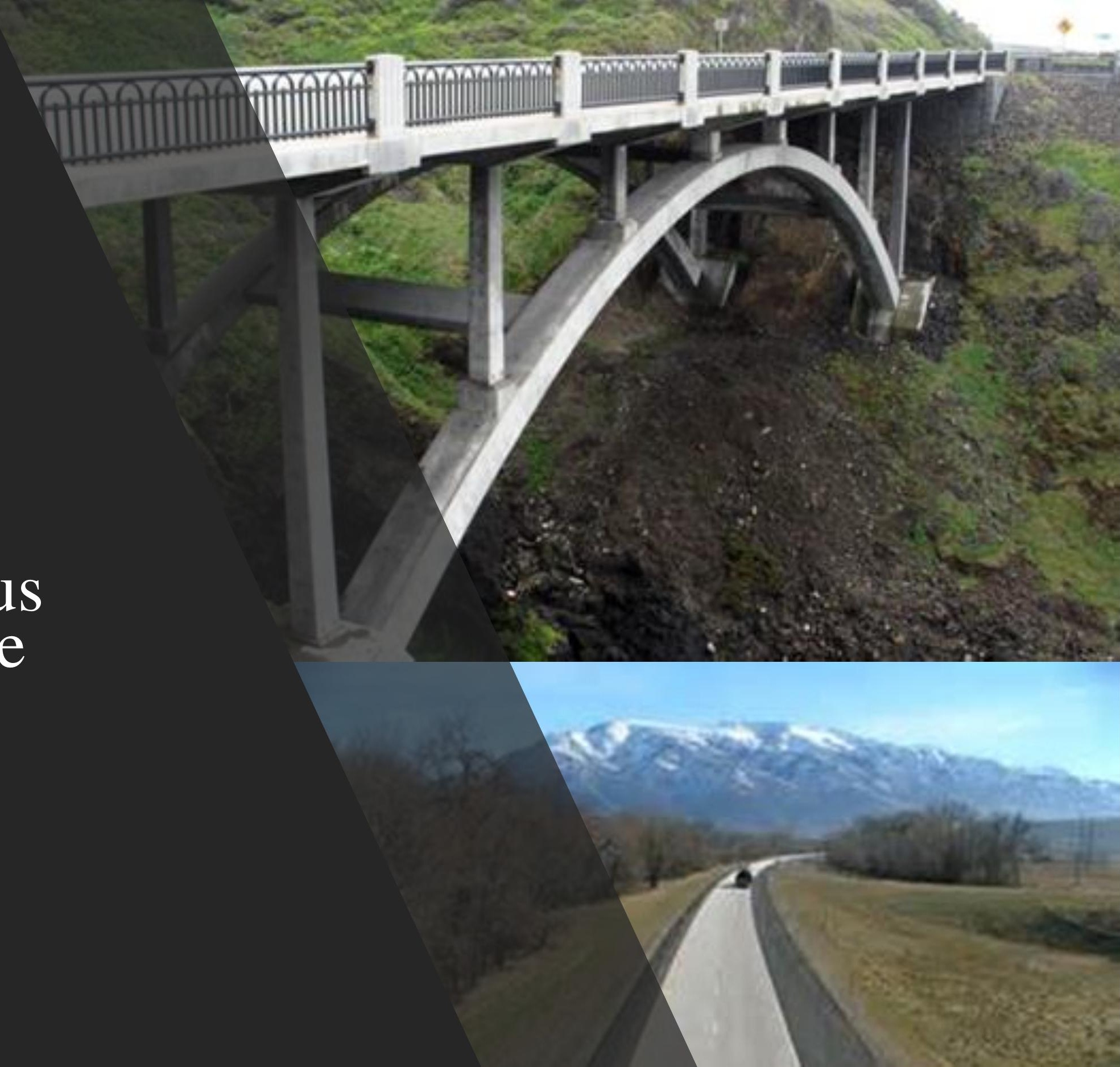




\section{Introduction}

- Corrosion is the biggest problem in the concrete structures and billions of dollars are used for the maintenance cost.

- It has become very important to develop High Performance Concrete (HPC) due to weathering problems in nation's concrete infrastructure namely bridges and pavements.

- HPC generally increases the durability against the chloride induced corrosion along with long term compressive and tensile strength.

- Therefore, a natural pozzolanic cementitious material known as natural zeolite is being used for enhancing the performance of HPC.

- Natural zeolite, a crystalline hydrated alumino-silicate processed (volcanic ash) mineral and its highly effective pozzolan due to natural occurrence of aluminum silicate. 


\section{Objectives}

- Identifying proper binary and ternary based HPC mixtures design with variation of feasible water to cementitious material ratio and different aggregate sizes.

- Surface electrical resistivity (SR) and modulus of elasticity testing is performed under the durability investigation against the chloride induced corrosion in concrete structures.

- Modulus of elasticity is related to stiffness and strength of concrete and it widely used in design of reinforcement concrete structures

- This SR data provides indirect indication to corrosion rate in reinforced concrete structures.

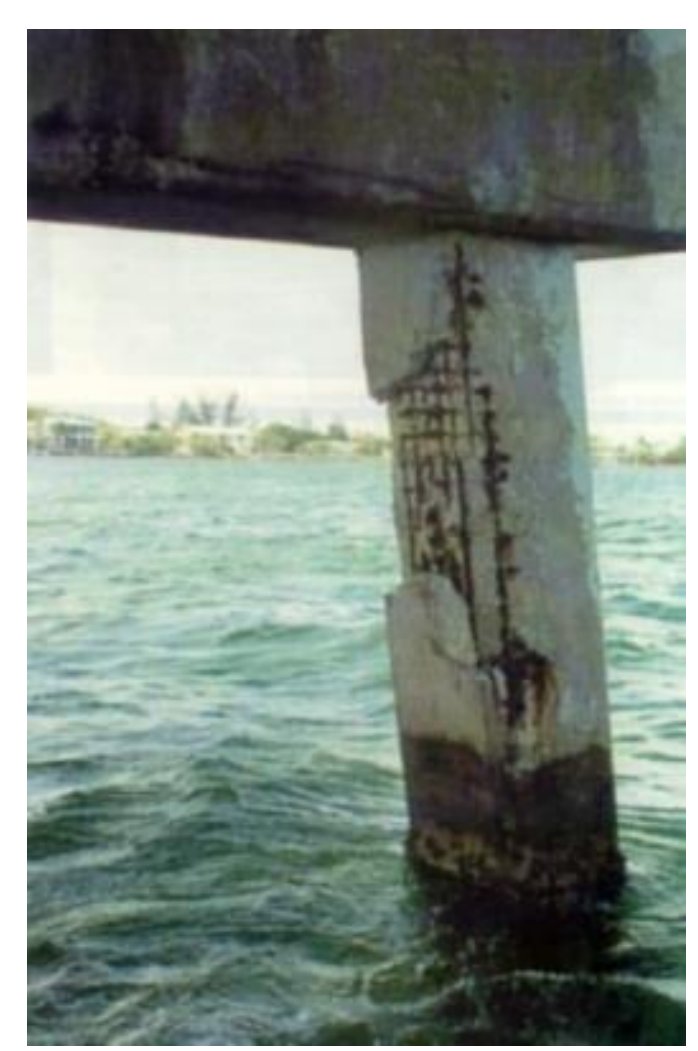

Ingress of corrosive species (into porous concrete)

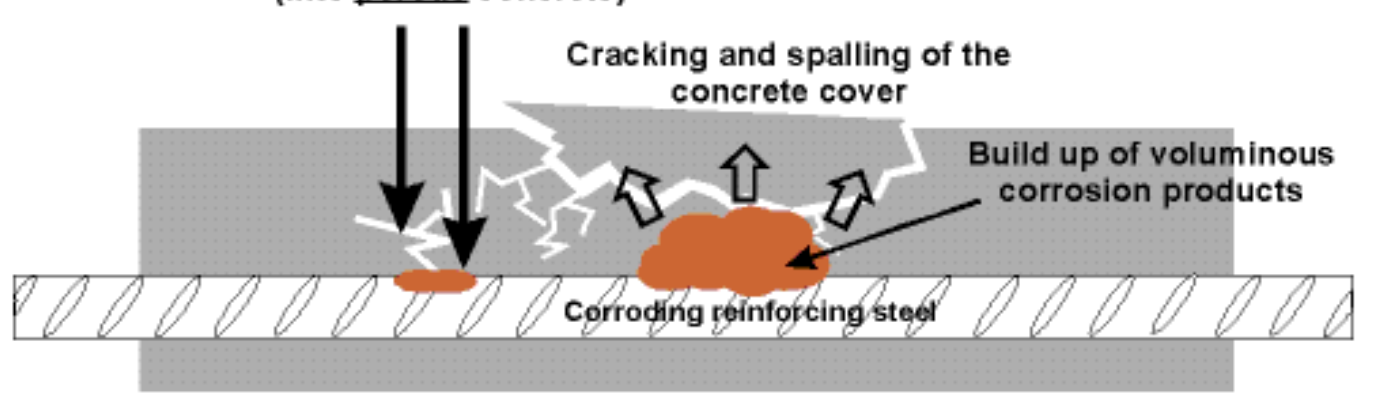




\section{Materials}

- Zeolite: major cementitious material being investigated

- Type II-V Cement (TII-V), since Type I Cement is prohibited in California due to sulfate attack problem

- Other Supplementary Cementitious Materials (SCMs):

- Ground granulated blast furnace slag of grade 120 (G120S)

- Class C Fly Ash (C)

- Class F Fly Ash (F)

- Silica Fume (SF)

- Metakaolin (M)

- Pumice (P)

- Chemical Admixtures

- Glenium 3030 water reducer (ASTM C494 Specification)

- MBVR Air Entrainer (ASTM C494 Specification) 


\section{Concrete Mixtures}

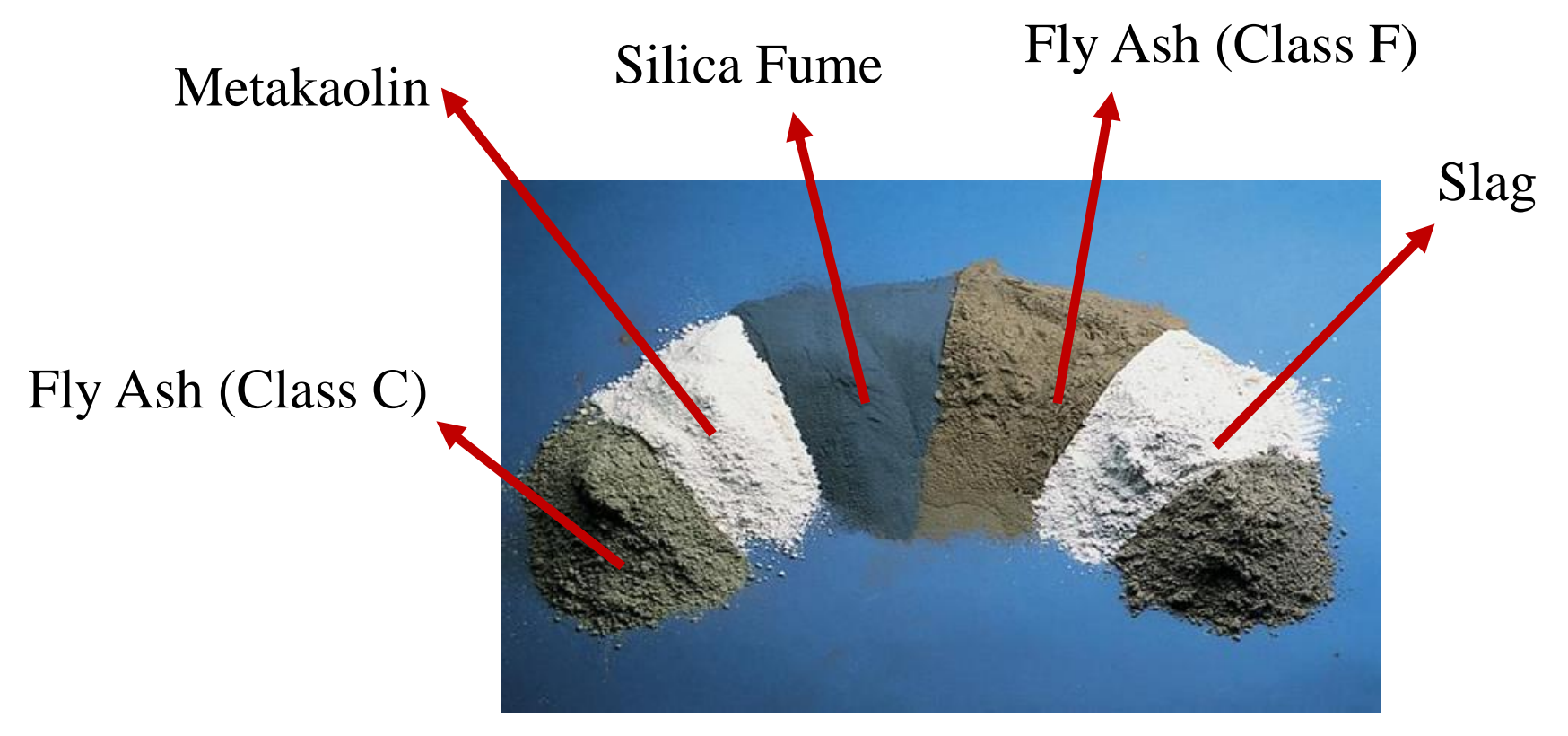

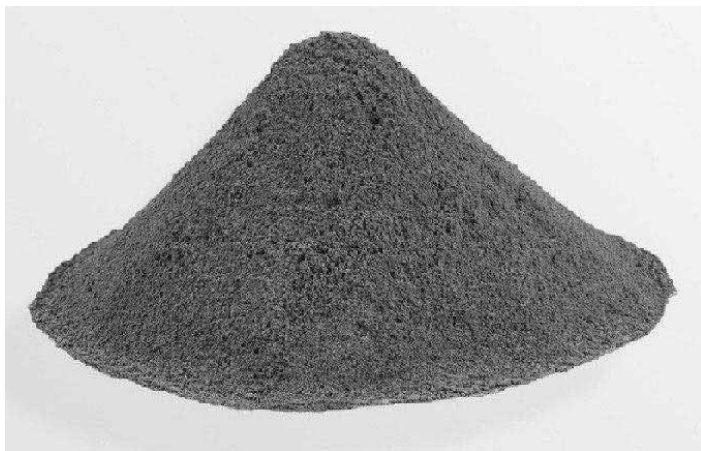

Ordinary Portland Cement (OPC)

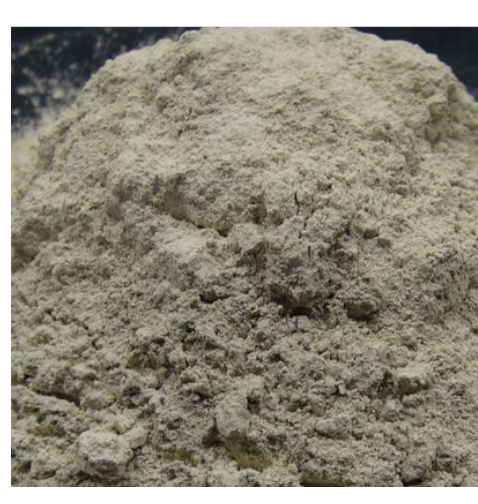

Zeolite (10\%, 15\%, $20 \%, 25 \%, 30 \%$ replacement by mass)
Binary based

- concrete mixtures

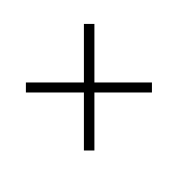




\section{Concrete Mixtures}

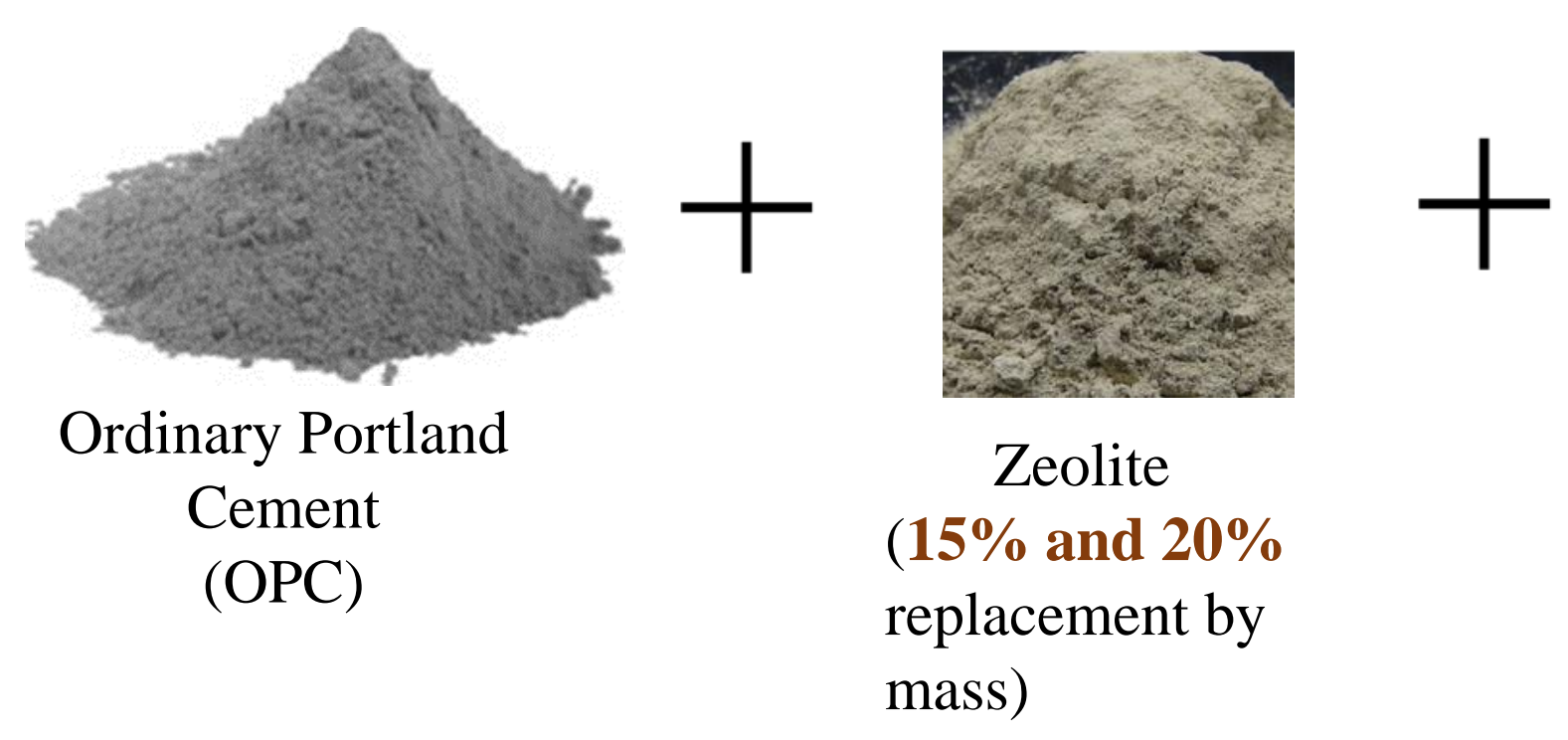

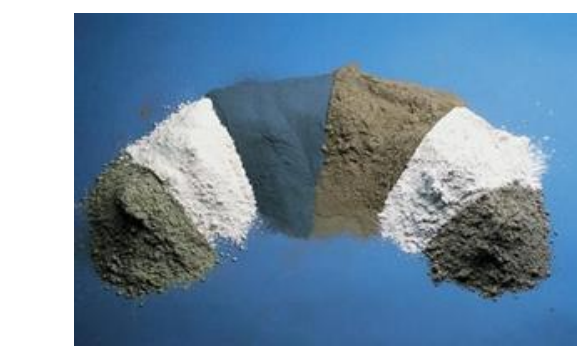

Supplementary

Cementitious materials (SCM)

- Water to cementitious material ratios (W/C) were kept at either 0.44 or 0.4

- Coarse aggregates of $1 / 2$ " or 3/4" were used in the mixtures

- Zeolite was replaced with cement with varying percentage level of 10, 15, 20,25 , and $30 \%$ by mass. 


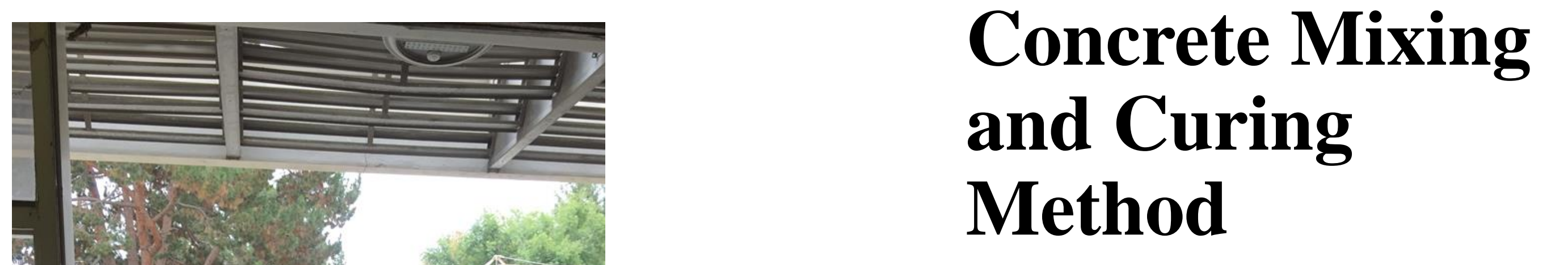

Mixing of

Concrete

(Left)

Curing of

Concrete Samples (Right)

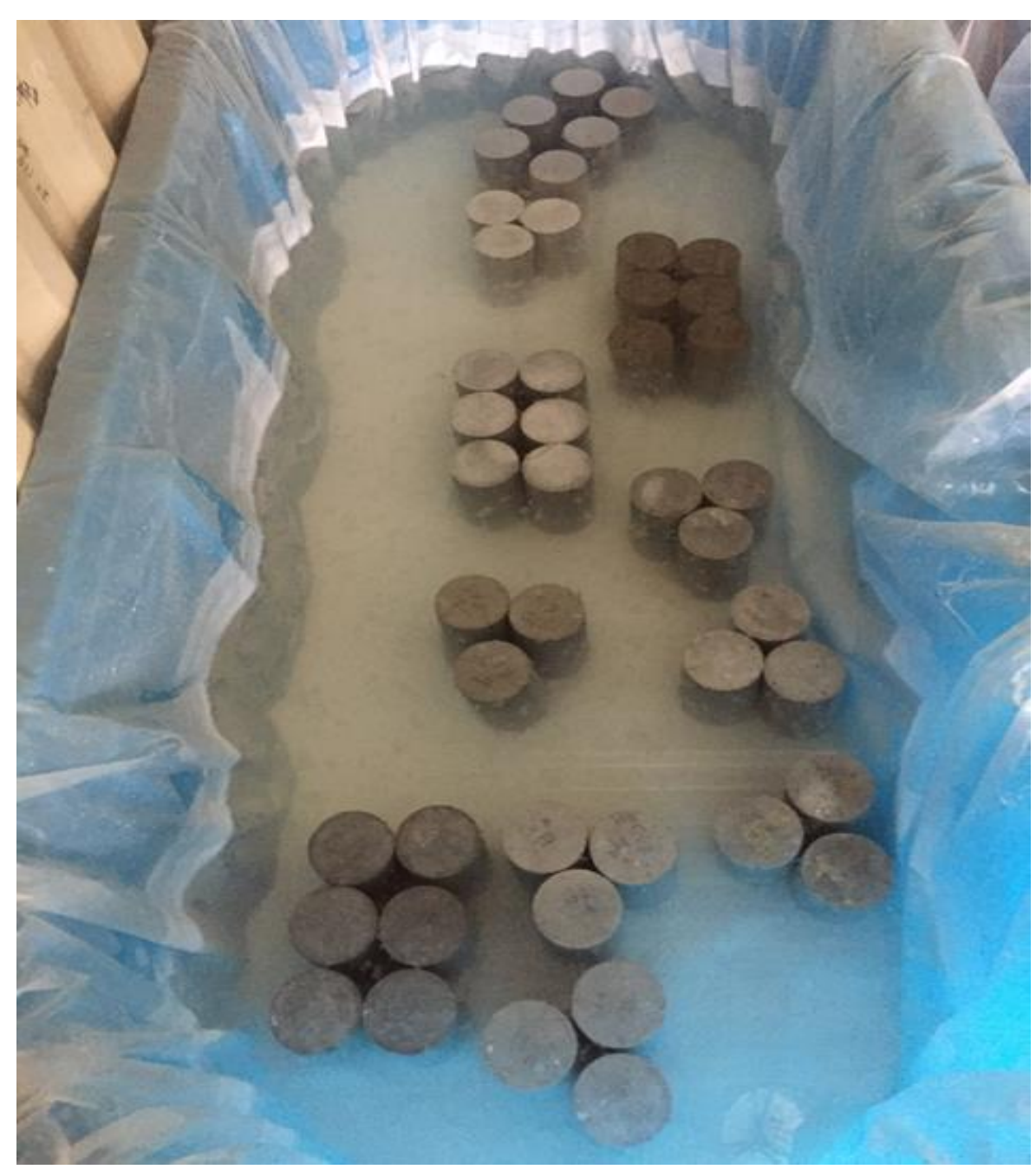




\section{Experimental Method}

- Cylinders of 4" diameter and 8" length were poured with concrete according to ASTM C192 specification.

- The cylinders were used for testing modulus of elasticity at 28 days and surface electrical resistivity at 7, 28, 56 and 91days.

- Concrete cylinders are cured in saturated lime water tank.

- 4- point Wenner Probe device is used as Non Destructive Testing for surface electrical resistivity.

- For modulus of elasticity compressometer is used as Destructive Testing.
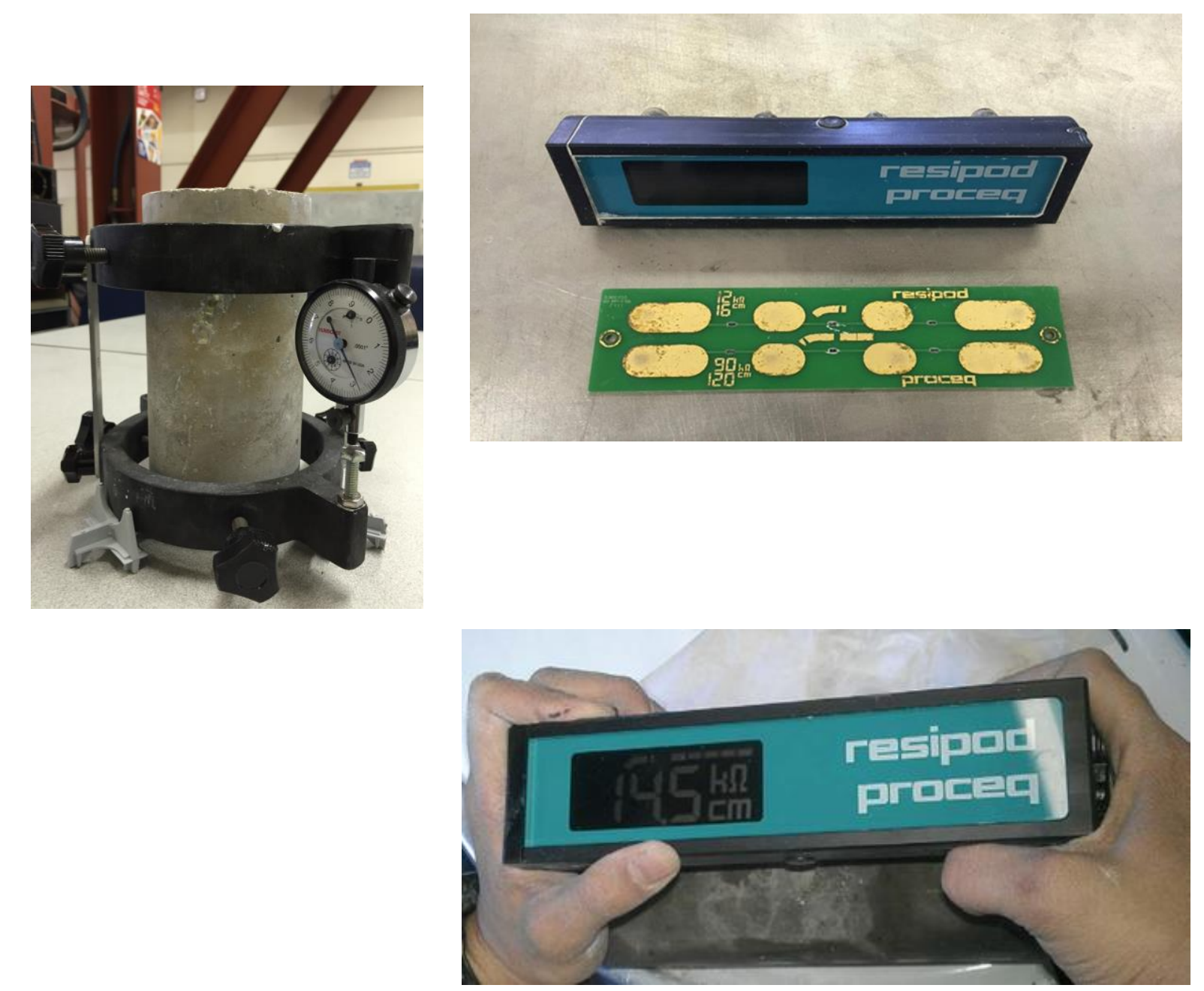


\section{Surface Electrical Resistivity}

- 3 Concrete cylinders are tested using 4- point Wenner Probe testing at 7, 28, 56 and 91 days.

\begin{tabular}{|l|l|}
\hline $\begin{array}{l}\text { Chloride Ion } \\
\text { Permeability }\end{array}$ & $\begin{array}{l}\text { Surface } \\
\text { Resistivity Test } \\
\mathrm{k} \Omega \text {-cm }\end{array}$ \\
\hline High & $<12$ \\
\hline Moderate & $12-21$ \\
\hline Low & $21-37$ \\
\hline Very Low & $37-254$ \\
\hline Negligible & $>254$ \\
\hline
\end{tabular}

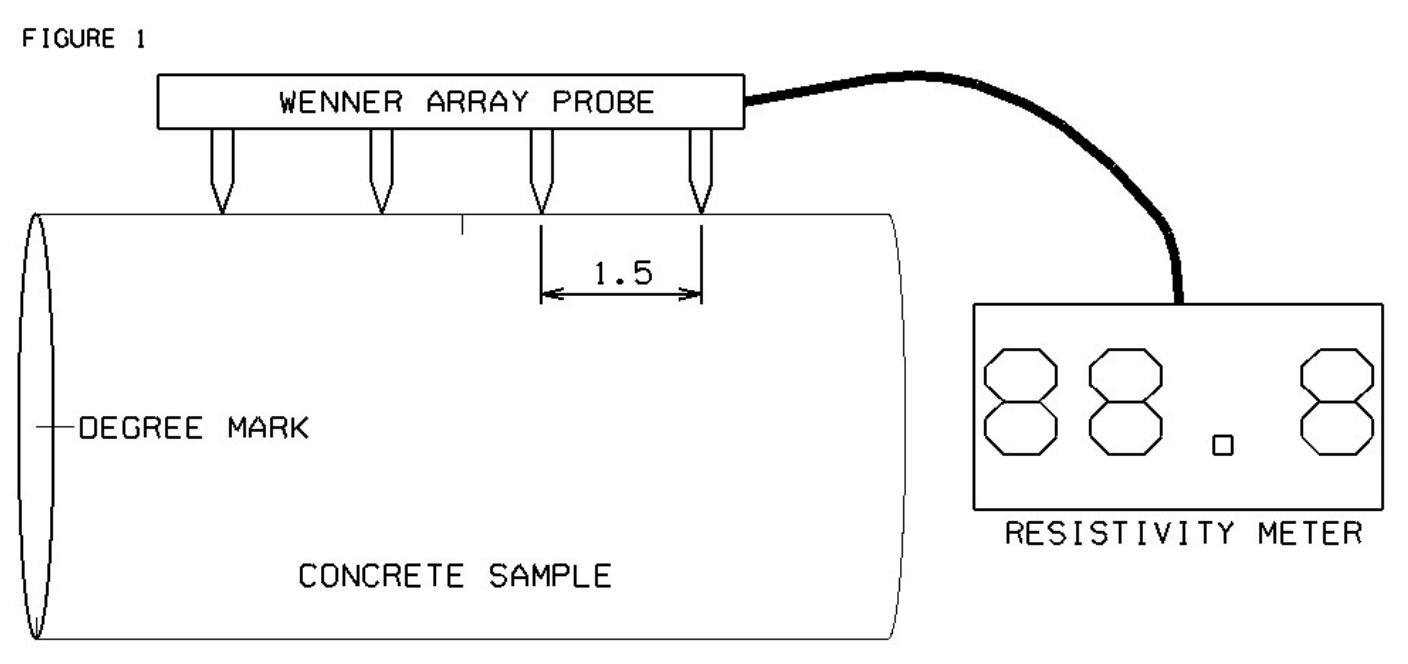

Surface Resistivity - Permeability From FDOT 


\section{Surface Electrical Resistivity}
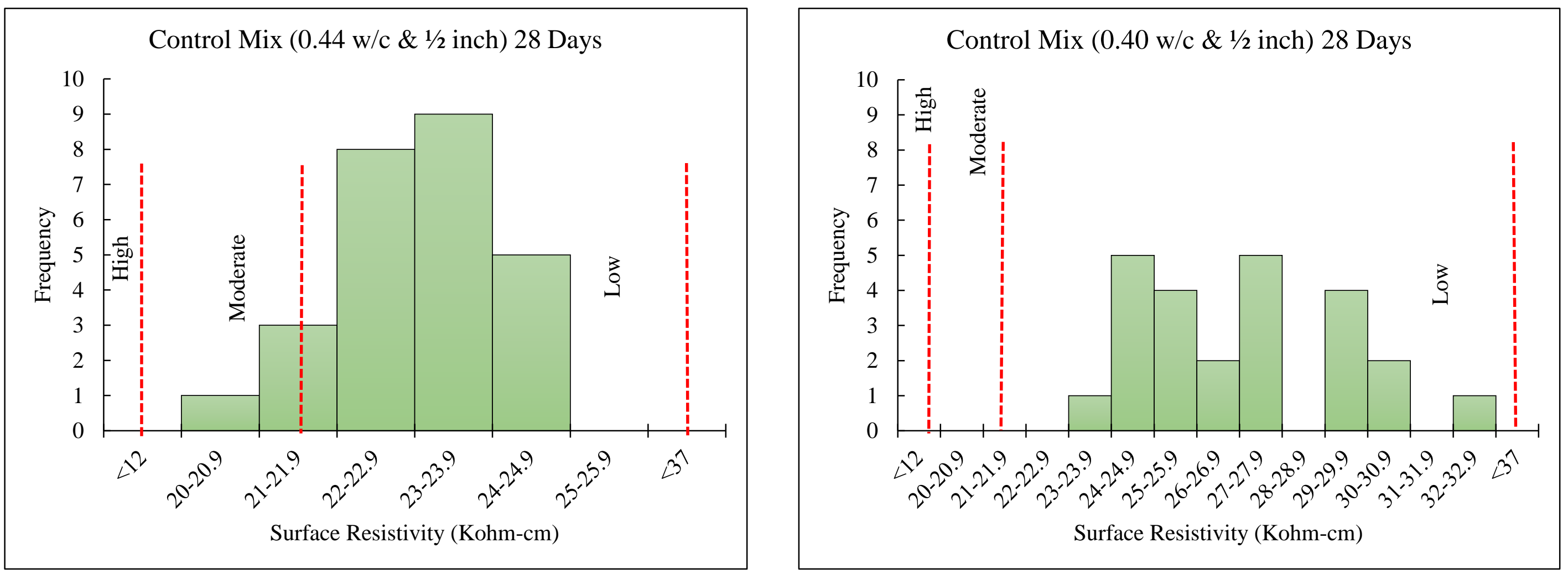

Figure 1: Comparison of surface electrical resistivity of Ordinary Portland Cement (OPC) to 0.44 with $0.40 \mathrm{w} / \mathrm{c}$ for $1 / 2$ " aggregate size 


\section{Surface Electrical Resistivity}
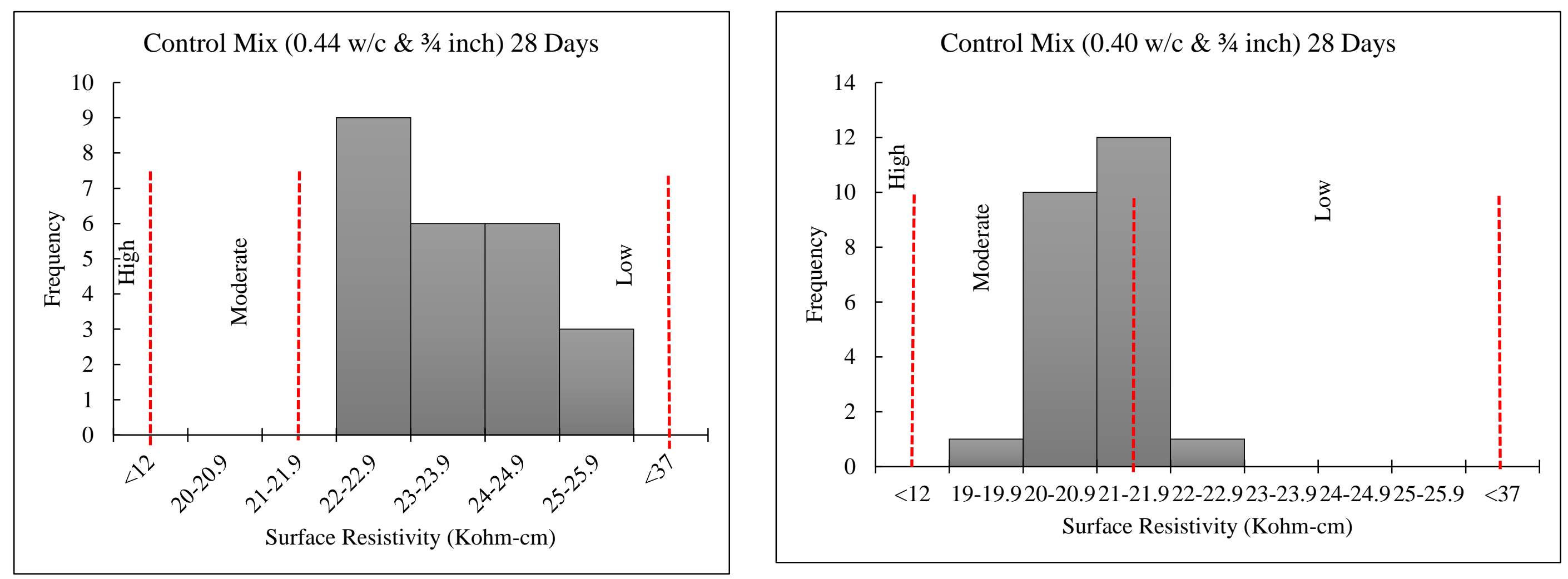

Figure 2: Comparison of surface electrical resistivity of Ordinary Portland Cement (OPC) to 0.44 with $0.40 \mathrm{w} / \mathrm{c}$ for $3 / 4$ " aggregate size 


\section{Surface Electrical Resistivity}
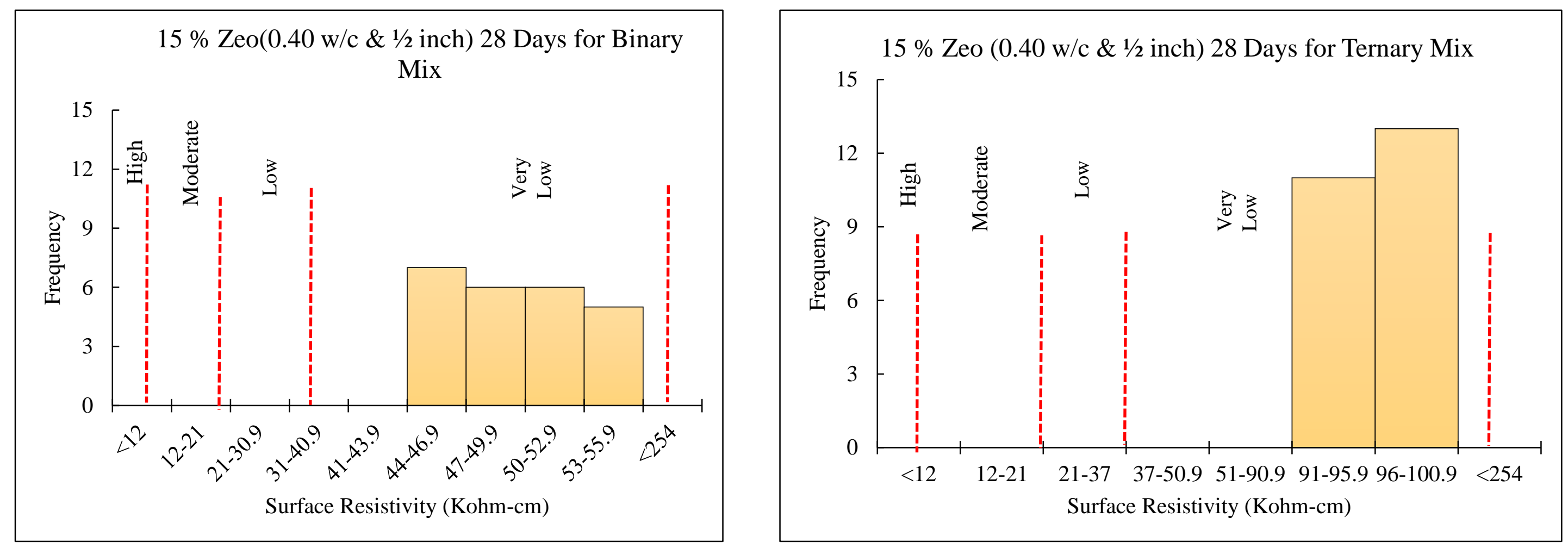

Mix Design

75TII-V/15Z/10SF

Figure 3: Comparison of surface electrical resistivity of binary to ternary mixture 


\section{Surface Electrical Resistivity}
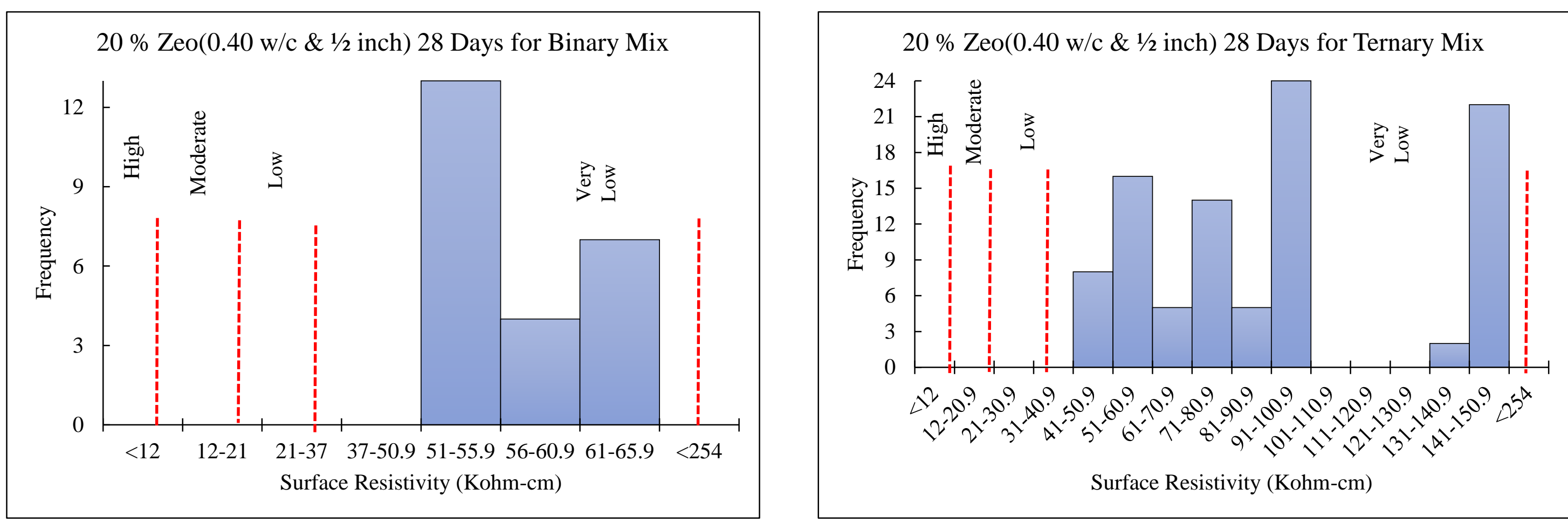

Mix Designs: 60TII-V/20Z/20F

Figure 4: Comparison of surface electrical 70TII-V/20Z/10M resistivity of binary to ternary mixture $55 \mathrm{TII}-\mathrm{V} / 20 \mathrm{Z} / 25 \mathrm{C}$ $55 \mathrm{TII}-\mathrm{V} / 20 \mathrm{Z} / 25 \mathrm{P}$ 


\section{Surface Electrical Resistivity}
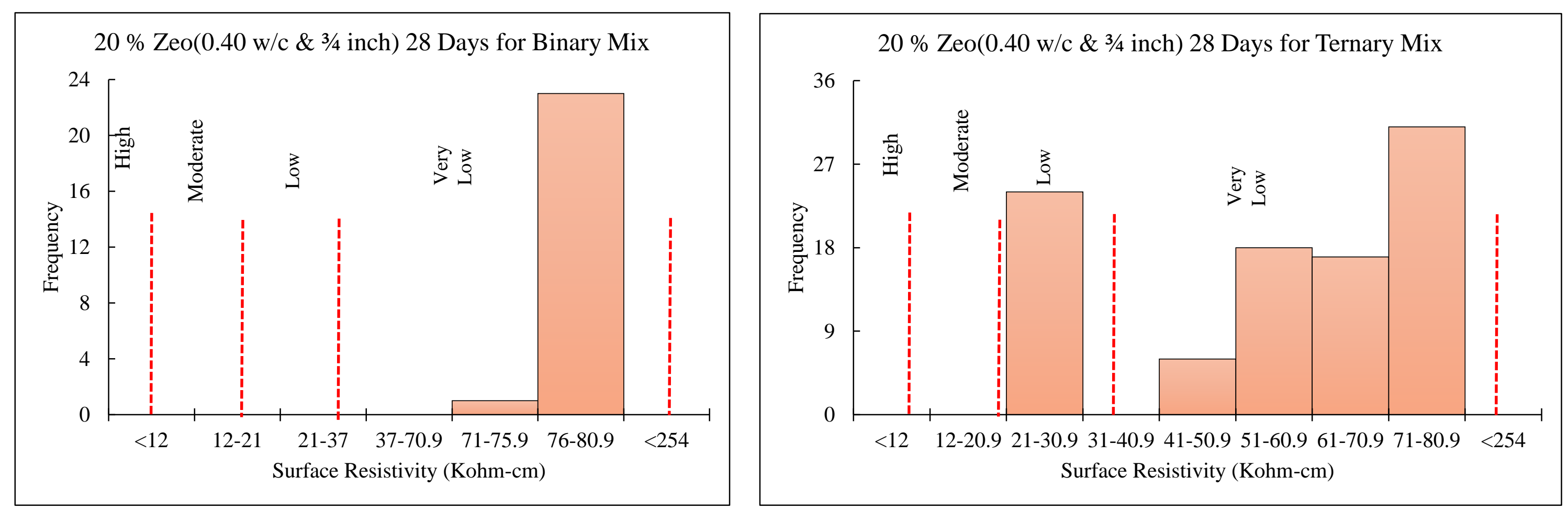

Mix Designs: $60 \mathrm{TII}-\mathrm{V} / 20 \mathrm{Z} / 20 \mathrm{~F}$

Figure 5: Comparison of surface electrical $70 \mathrm{TII}-\mathrm{V} / 20 \mathrm{Z} / 10 \mathrm{M}$ resistivity of binary to ternary mixture $55 \mathrm{TII}-\mathrm{V} / 20 \mathrm{Z} / 25 \mathrm{C}$ $55 \mathrm{TII}-\mathrm{V} / 20 \mathrm{Z} / 25 \mathrm{P}$ 


\section{Modulus of Elasticity}

- Modulus of Elasticity is tested at 28 days and average for 2 cylinders is taken into account.

- Measuring Modulus of Elasticity (E) is obtained:

- Theoretically : using this equation, $E=57,000 \sqrt{f_{c}}$

- Graphically : based on slope of strain and stress curve within an elastic deformation region

- Experimentally : using compressometer equipment

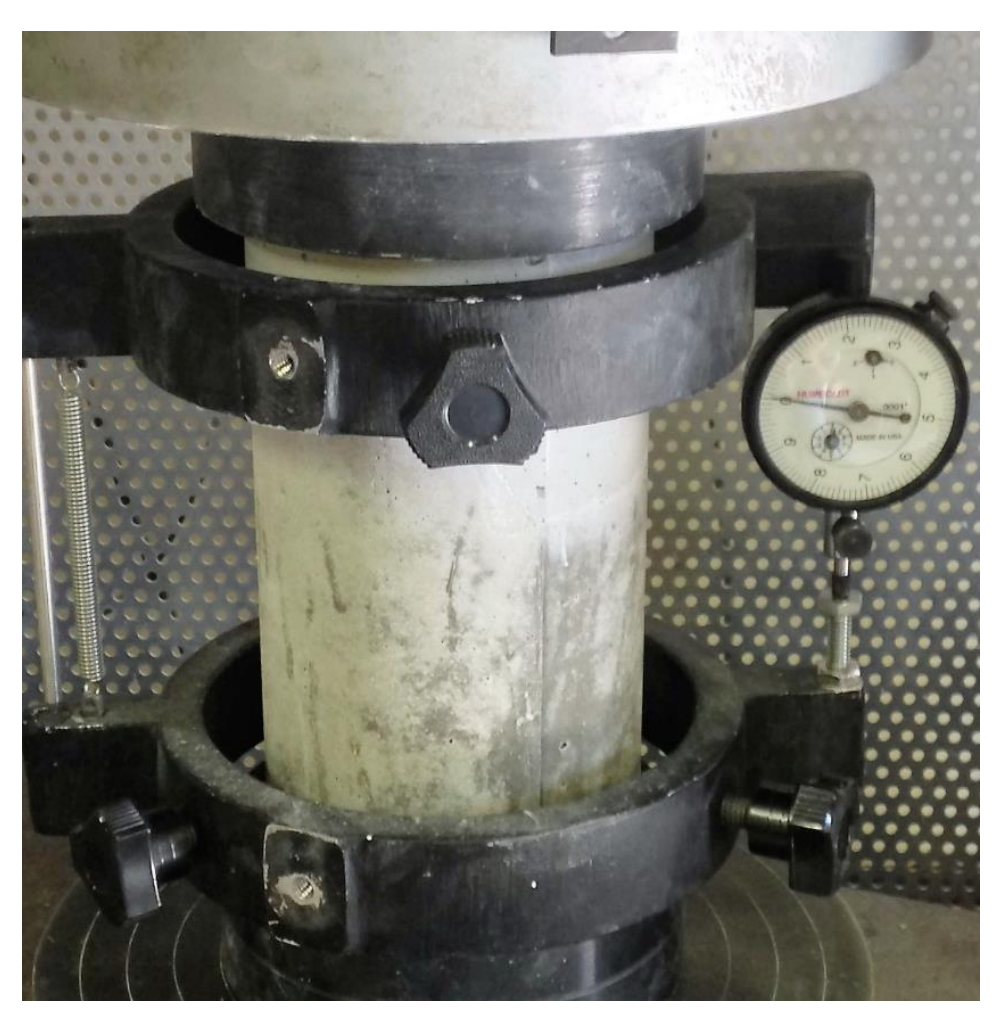




\section{Modulus of Elasticity}
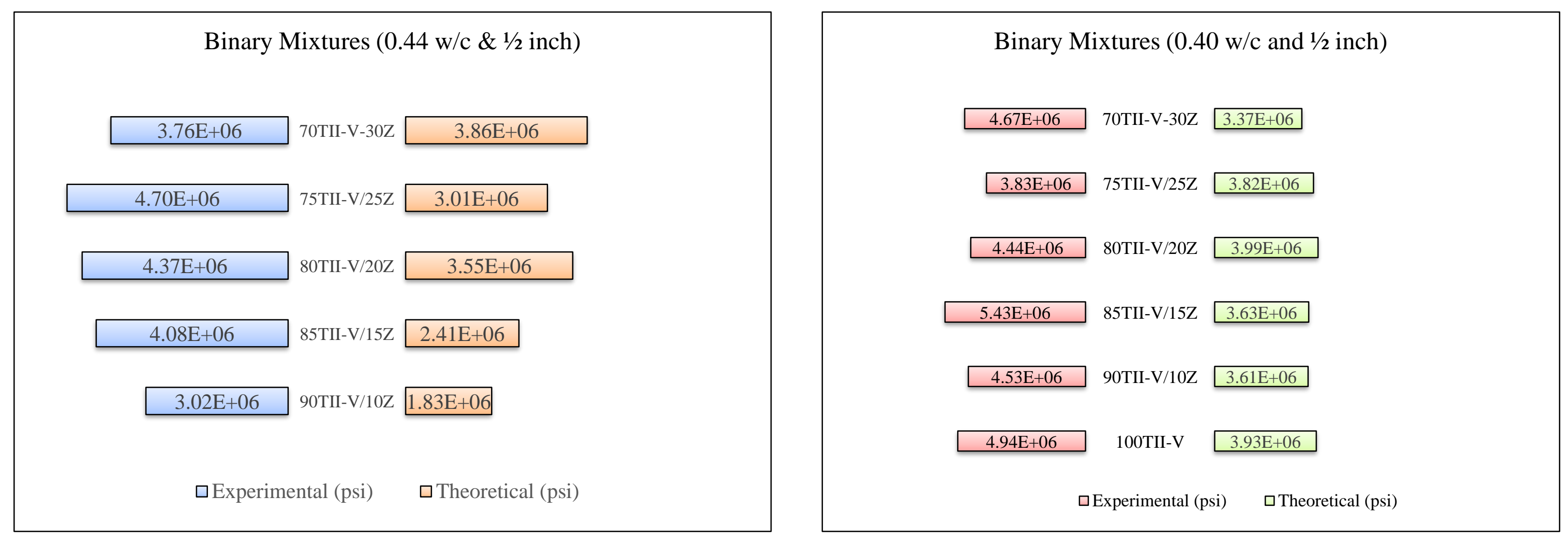

Figure 6: Comparison of experimental to theoretical modulus of elasticity for binary mixtures 


\section{Modulus of Elasticity}
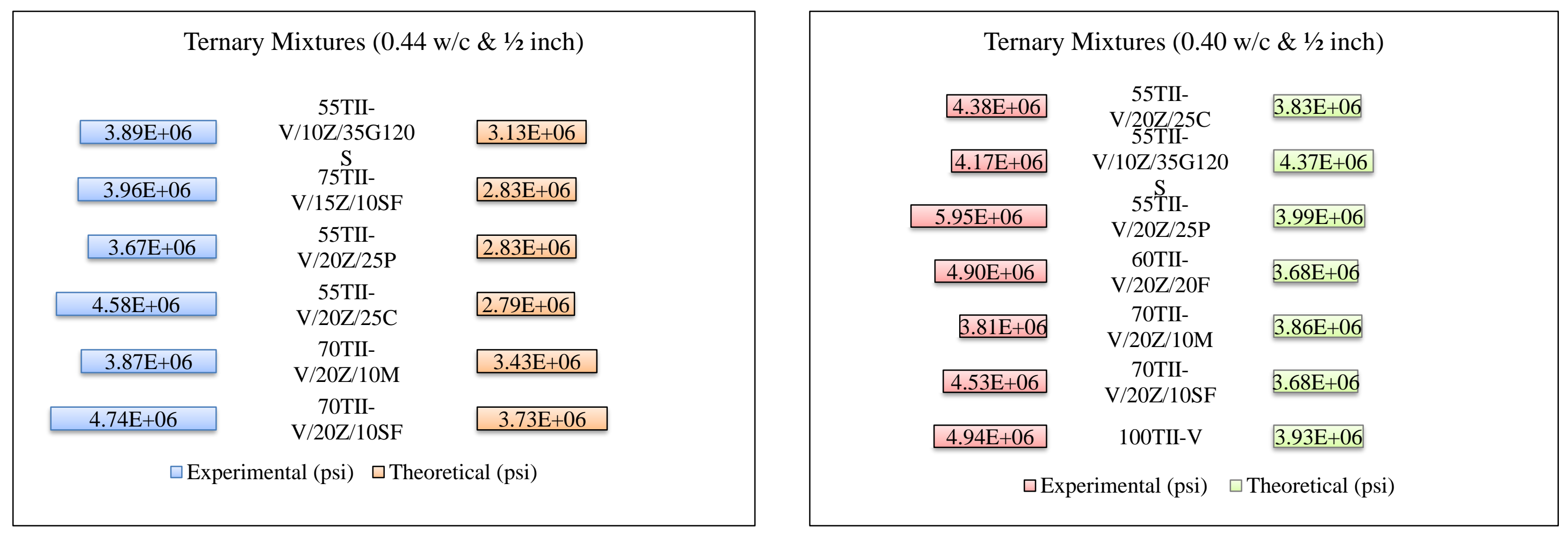

Figure 7: Comparison of experimental to theoretical modulus of elasticity for ternary mixtures 


\section{Modulus of Elasticity}
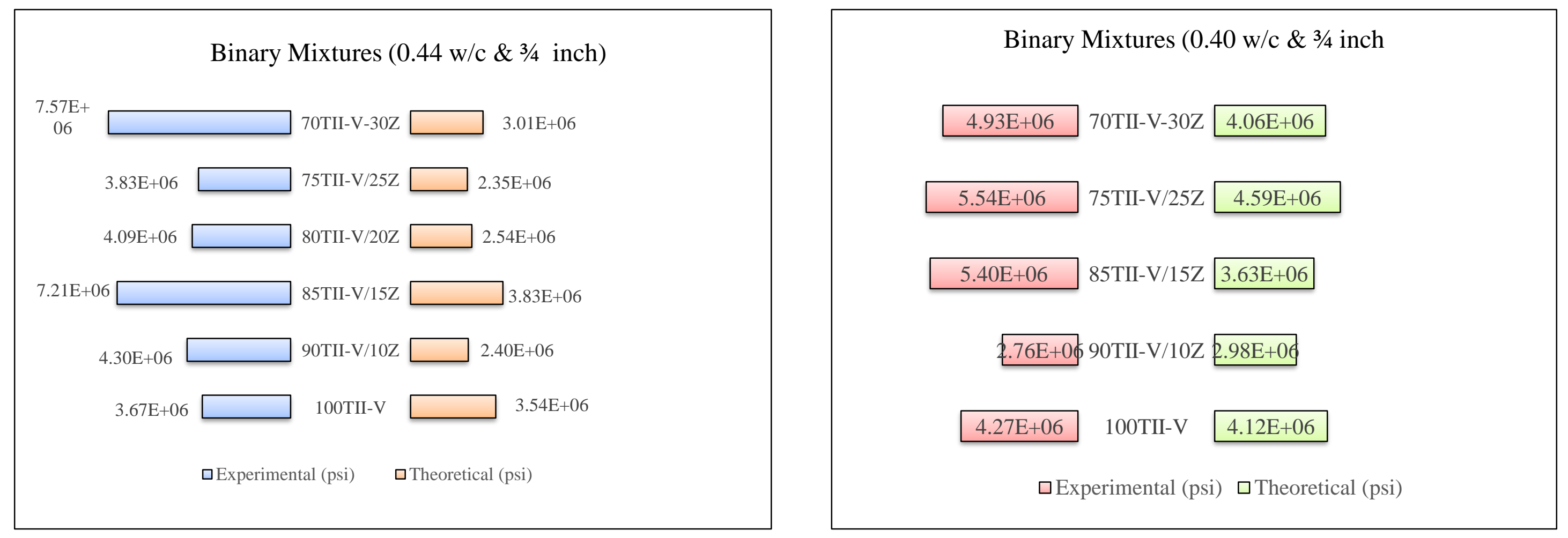

Figure 8: Comparison of experimental to theoretical modulus of elasticity for binary mixtures 


\section{Conclusions}

- Zeolite based concrete mixtures with water to total cementitious material ratio $(\mathrm{W} / \mathrm{C})$ at 0.4 and $3 / 4$ " aggregates provide promising results in terms of development of high surface electrical resistivity and modules of elasticity .

- Results for modulus of elasticity for theoretical and experimental are within 10 to $20 \%$ of error of margin and this is acceptable.

- Based on the analysis, it can be concluded that zeolite is very sensitive to $\mathrm{W} / \mathrm{C}$ ratios and size of the aggregates.

- In summary, zeolite based concrete mixtures achieved low corrosion rate and will increase the service life due to chloride induced corrosion. 


\section{Acknowledgment}

- I am grateful to my professor Dr. Pratanu Ghosh for giving me a chance to do research under his guidance. I also want to thank following people for supporting our research sponsoring required materials.

- Ken Sears (Fly Ash)

- Paul Heis, BASF (Silica fume and Chemical admixtures like MBVR and Glenium 3030)

- Gary Kirk (Calportland Cement for Type II-V) 


\section{Questions?}

